\title{
Ultra-high molecular weight hydrophobic acrylic and styrenic polymers through organic-phase photoiniferter-mediated polymerization
}

R. Nicholas Carmean, ${ }^{\dagger}$ Michael B. Sims,${ }^{\dagger}$ C. Adrian Figg, ${ }^{\dagger}$ Paul J. Hurst, ${ }^{\ddagger}$ Joseph P. Patterson, ${ }^{\ddagger}$ and Brent S. Sumerlin ${ }^{+*}$

${ }^{\dagger}$ George \& Josephine Butler Polymer Research Laboratory, Center for Macromolecular Science \& Engineering, Department of Chemistry, University of Florida, Gainesville, FL 32611, USA.

${ }^{\ddagger}$ Department of Chemistry, University of California Irvine, 1102 Natural Sciences II, Irvine, CA 92697, USA

*Email: Sumerlin@chem.ufl.edu

Table of Contents

2) Materials and characterization

3) Experimental procedure

4) Figure S1. Polymerization of methyl acrylate

5) Figure S2. Polymerization of methyl acrylate to ultra-high molecular weight

6) Figure S3. Polymerization of methyl acrylate to a degree of polymerization over 60,000

7) Figure S4. Polymerization of $\mathrm{N}, \mathrm{N}$-dimethyl acrylamide to ultra-high molecular weight

8) Figure S5. Polymerization of $\mathrm{N}$-acryloyl morpholine to ultra-high molecular weight

9) Figure S6. Polymerization of $\mathrm{N}$-isopropyl acrylamide to ultra-high molecular weight

10) Figure S7. Synthesis of ultra-high molecular weight PMA-b-PMA

Figure S8. Synthesis and self-assembly of ultra-high molecular weight PMA-b-PDMA

11) Figure S9. Synthesis and self-assembly of ultra-high molecular weight PMA-b-PNAM

12) Figure S10. Polymerization of methyl methacrylate to ultra-high molecular weight

13) Figure S11. Alternating copolymerization of styrene-alt-maleic anhydride to ultra-high molecular weight

14) Figure S12. Alternating copolymerization of styrene-alt-benzyl maleimide to ultra-high molecular weight 


\section{Materials}

All chemicals were used as received unless otherwise noted. 2-(2carboxyethylsulfanylthiocarbonylsulfanyl)-2-methylpropionic acid and 4-cyano-4(phenylcarbonothioylthio)pentanoic acid were synthesized according to previous reports. ${ }^{[1,2]}$ Methyl acrylate (MA, Sigma-Alrich, 99\%), N, N-dimethylacrylamide (DMA, Sigma-Aldrich, 99\%), $N$ acryloylmorpholine (NAM, Sigma-Aldrich, 97\%), methyl methacrylate (MMA, Sigma-Aldrich, 99\%), styrene (S, Sigma-Aldrich, 99\%), and dioxane were passed through a column of basic alumina to remove inhibitors and acidic impurities prior to use. $N$-Isopropylacrylamide (NIPAM) was recrystallized from acetone three times prior to use. The UV light $\left(7.0 \mathrm{~mW} / \mathrm{cm}^{2}\right)$ was supplied from a UV nail gel-curing lamp (available online from ad hoc suppliers) with four $9 \mathrm{~W}$ bulbs and a peak emission near $365 \mathrm{~nm}$. The blue light was supplied from a commercially available blue LED light strip (SuperbrightLEDs.com, $50 \mathrm{~cm}, 0.9 \mathrm{~W} / \mathrm{ft}, 16459 \mathrm{mcd} / \mathrm{ft}$ ) wound inside a $100 \mathrm{~mL}$ beaker wrapped in aluminum foil.

Nuclear Magnetic Resonance (NMR) Spectroscopy. ${ }^{1} \mathrm{H}$ NMR spectra were recorded in deuterated chloroform $\left(\mathrm{CDCl}_{3}\right.$, Cambridge Isotopes), deuterated dimethyl sulfoxide (DMSO- $d_{6}$, Cambrdge Isotopes), or deuterium oxide $\left(\mathrm{D}_{2} \mathrm{O}\right.$, Cambridge Isotopes) using a Varian Mercury 300 or Varian Inova $500 \mathrm{MHz}$ spectrometer.

Size Exclusion Chromatography (SEC). Molecular weights and molecular weight distributions were determined via multi-angle laser light scattering size exclusion chromatography (MALSSEC) in N,N-dimethylacetamide (DMAc) with $50 \mathrm{mM} \mathrm{LiCl}$ at $50{ }^{\circ} \mathrm{C}$ and a flow rate of $1.0 \mathrm{~mL} / \mathrm{min}$ (Agilent isocratic pump, degasser, and autosampler; ViscoGel I-series $10 \mu \mathrm{m}$ guard column and two ViscoGel I-series G3078 mixed bed columns, with molecular weight ranges $0-20 \times 10^{3}$ and $0-10 \times 10^{6} \mathrm{~g} / \mathrm{mol}$, respectively). Detection consisted of a Wyatt Optilab T-rEX refractive index detector operating at $658 \mathrm{~nm}$ and a Wyatt miniDAWN Treos light scattering detector operating at $659 \mathrm{~nm}$. Absolute molecular weights and polydispersities were calculated using Wyatt ASTRA software. The absolute molecular weight for PDMA was determined using $100 \%$ mass recovery, a multiangle light scattering detector and Wyatt ASTRA software. Each polymer was dehydrated by lyophilization and dissolved in SEC solvent $(\leq 1 \mathrm{mg} / \mathrm{mL})$ at least $24 \mathrm{~h}$ prior to molecular weight characterization.

Gas chromatography. All measurements were performed on a Molecular Devices SpectraMax $\mathrm{M} 2$ Multimode Microplate Reader at $25^{\circ} \mathrm{C}$. Absorbance measurements were conducted with $150 \mu \mathrm{L}$ of sample on clear 96-well microplates (Greiner). Calibration curves and path length correction were constructed using the integrated SoftMax Pro software.

Light Intensity was measured with General UV513AB Digital UV AB Light Meter calibrated at $365 \mathrm{~nm}$.

Cryogenic Transmission Electron Microscopy (cryogenic TEM). Cryogenic TEM Quantifoil R 2/2 grids were purchased from Electron Microscopy Sciences. Grids were glow discharged for $70 \mathrm{~s}$ 
to increase hydrophilicity. Vitrification was carried out using an Automatic Plunge Freezer ME GP2 (Leica Microsystems) where self-assembled samples were loaded onto the glow-discharged grids at $95 \%$ humidity to prevent evaporation and blotted for $3 \mathrm{~s}$ before autoplunging into liquid propane. Vitrified samples were studied on a JEOL-2100 F TEM using a Schottky type field emission gun operating at $200 \mathrm{kV}$. Images were recorded using Digital Micrograph software and a Gatan OneView CMOS camera at 4k x 4k resolution. 


\section{Experimental}

Typical ultra-high molecular weight polymerization procedure (MA polymerization initiated and mediated by a trithiocarbonate targeting $M_{\mathrm{n}} \geq 5.00 \times 10^{6} \mathrm{~g} / \mathrm{mol}$ ). MA (860 mg, $9.99 \mathrm{mmol}$ ) and trithiocarbonate iniferter $\left(25.0 \mu \mathrm{g}, 9.32 \times 10^{-5} \mathrm{mmol}\right.$ from $1.00 \mathrm{mg} / \mathrm{mL}$ DMSO stock solution) were dissolved in DMSO (1.00 mL, $4 \mathrm{M}[\mathrm{MA}])$ in a $20 \mathrm{~mL}$ septa-capped scintillation vial and DMF $(100 \mu \mathrm{L})$ was added as an internal standard. The iniferter stock solution was stored between $2^{\circ} \mathrm{C}$ and $6^{\circ} \mathrm{C}$ for further use. A small volume was removed to determine monomer evaporation during purging, 25\% MA evaporation is expected. The polymerization solution was then frozen with liquid nitrogen and purged with argon with four $1 \mathrm{~mL}$ syringes through the septa. Once the solution thawed, argon was bubbled through the solution for $5 \mathrm{~min}$. With the $1 \mathrm{~mL}$ syringes, the polymerization solution $(150 \mu \mathrm{L})$ was transferred to argon-purged $4 \mathrm{~mL}$ reaction vials and assembled into the UV chamber such that each reaction vial was positioned $2.50 \mathrm{~cm}$ from the UV light source for an intensity of $7.0 \mathrm{~mW} / \mathrm{cm}^{2}$. The polymerization was initiated upon irradiation. At predetermined intervals, a single reaction vial was quenched and monomer conversion was determined with $\mathrm{GC}$, monitoring the disappearance of the monomer in relation to DMF. A sample of each reaction aliquot was dissolved in SEC solvent $(\leq 1 \mathrm{mg} / \mathrm{mL})$ at least $24 \mathrm{~h}$ prior to molecular weight characterization.

Typical ultra-high molecular weight block copolymer polymerization procedure (PMA- $b$ PNAM). MA (615 mg, $7.14 \mathrm{mmol})$ and trithiocarbonate iniferter $\left(0.100 \mathrm{mg}, 3.72 \times 10^{-4} \mathrm{mmol}\right.$ from $1.00 \mathrm{mg} / \mathrm{mL}$ DMSO stock solution) were dissolved in DMSO (0.800 mL $4 \mathrm{M}[\mathrm{MA}])$ in a $10 \mathrm{~mL}$ Schlenk flask and DMF $(0.100 \mathrm{~mL})$ was added as an internal standard. A small volume was removed to determine monomer evaporation during purging, 25\% MA evaporation is expected. The polymerization solution was frozen with liquid nitrogen and purged with argon. Once the solution thawed, argon was bubbled through the solution for $5 \mathrm{~min}$. The reaction vessel was positioned $2.50 \mathrm{~cm}$ from the UV light source for an intensity of $7.0 \mathrm{~mW} / \mathrm{cm}^{2}$ and polymerization was initiated upon irradiation. The reaction was irradiated for $8 \mathrm{~h}$ and a small amount was removed to determine monomer conversion with GC, monitoring the disappearance of the monomer in relation to DMF, and to characterize molecular weight via SEC. The polymerization MA reached $>95 \%$ monomer conversion. NAM $(660 \mathrm{mg}, 4.67 \mathrm{mmol}$ ) was dissolved in DMSO $(0.560 \mathrm{~mL}), \mathrm{DMF}(0.050 \mathrm{~mL})$, and the preceding PMA polymerization mixture in the Schlenk flask. Argon was bubbled through the viscous solution for $20 \mathrm{~min}$ and chain extension was initiated upon irradiation.

Typical ultra-high molecular weight polymerization procedure for alternating copolymers. Alternating copolymerizations were conducted according to the same typical procedure for homopolymers with the following changes: an equimolar ratio of styrene and maleic anhydride/maleimide were used as comonomers, 4-cyano-4(phenylcarbonothioylthio)pentanoic acid was used as the photoiniferter, and dioxane was used as the solvent. 


\section{Self-Assembly procedure for PDMA- $b$-PtBA}

PDMA- $b$-PtBA (5.19 mg) was dissolved in THF $(1 \mathrm{~mL})$ to form a clear solution. Milli-Q ( $\rho>18 \mathrm{M} \Omega$ $\mathrm{cm})$ water $(10 \mathrm{uL})$ was added to the PDMA- $b$-PtBA solution under stirring (500 rpm). The solution immediately displayed the Tyndall effect (blue tint) indicating self-assembly had taken place. The solution was stirred for 12 hours. To kinetically trap the assemblies, the PDMA- $b$-PtBA solution $(0.2 \mathrm{~mL})$ was added to Milli-Q $(\rho>18 \mathrm{M} \Omega \mathrm{cm})$ water $(0.8 \mathrm{~mL})$. The solution was then dialyzed against Milli-Q $(\rho>18 \mathrm{M} \Omega \mathrm{cm})$ water to remove the THF. The final polymer concentration was $1.04 \mathrm{mg} / \mathrm{mL}$. 


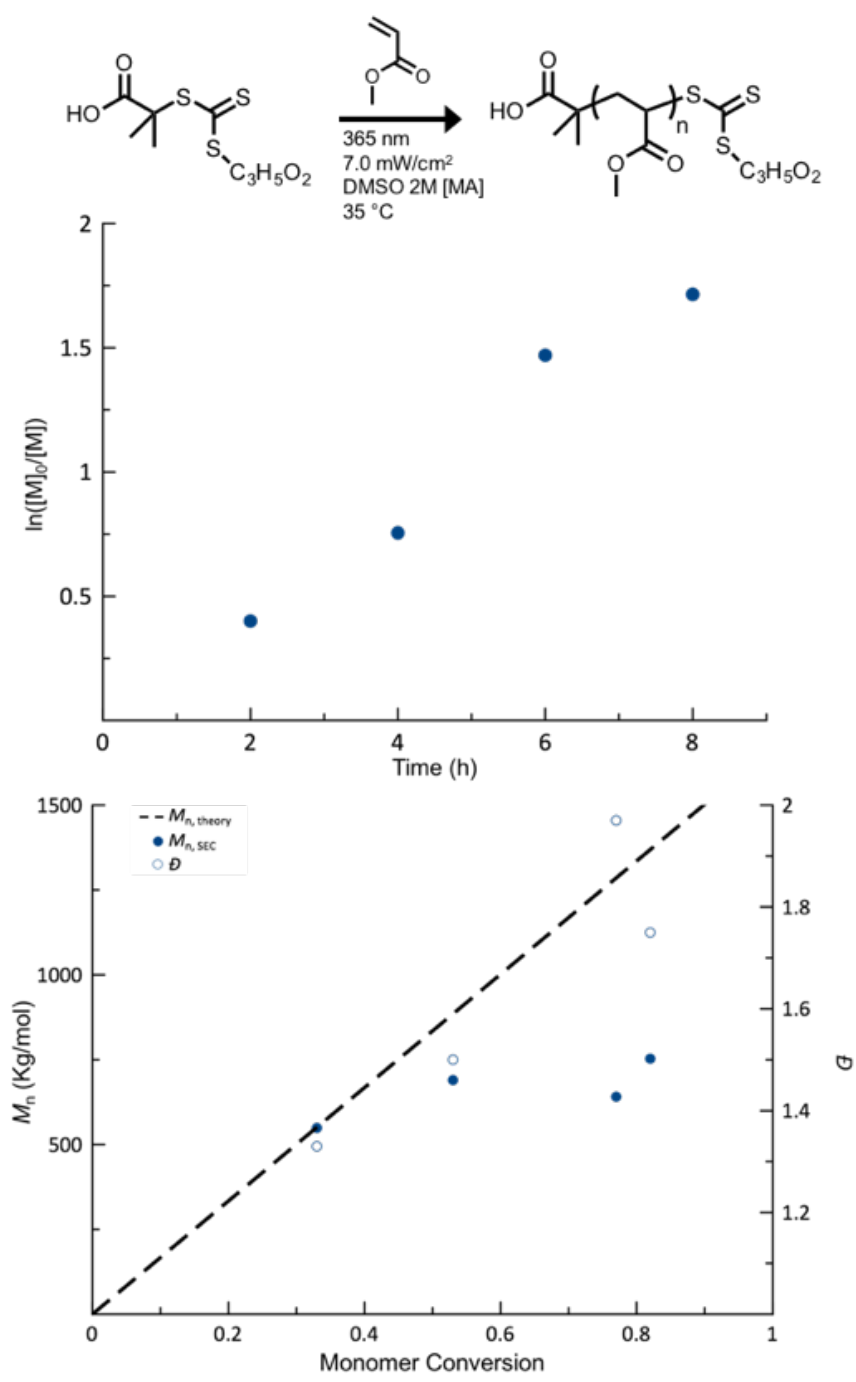

Figure S1. Attempts to synthesize UHMW poly(methyl acrylate) at low monomer concentrations lead to a loss of molecular weight control at high monomer conversion. 

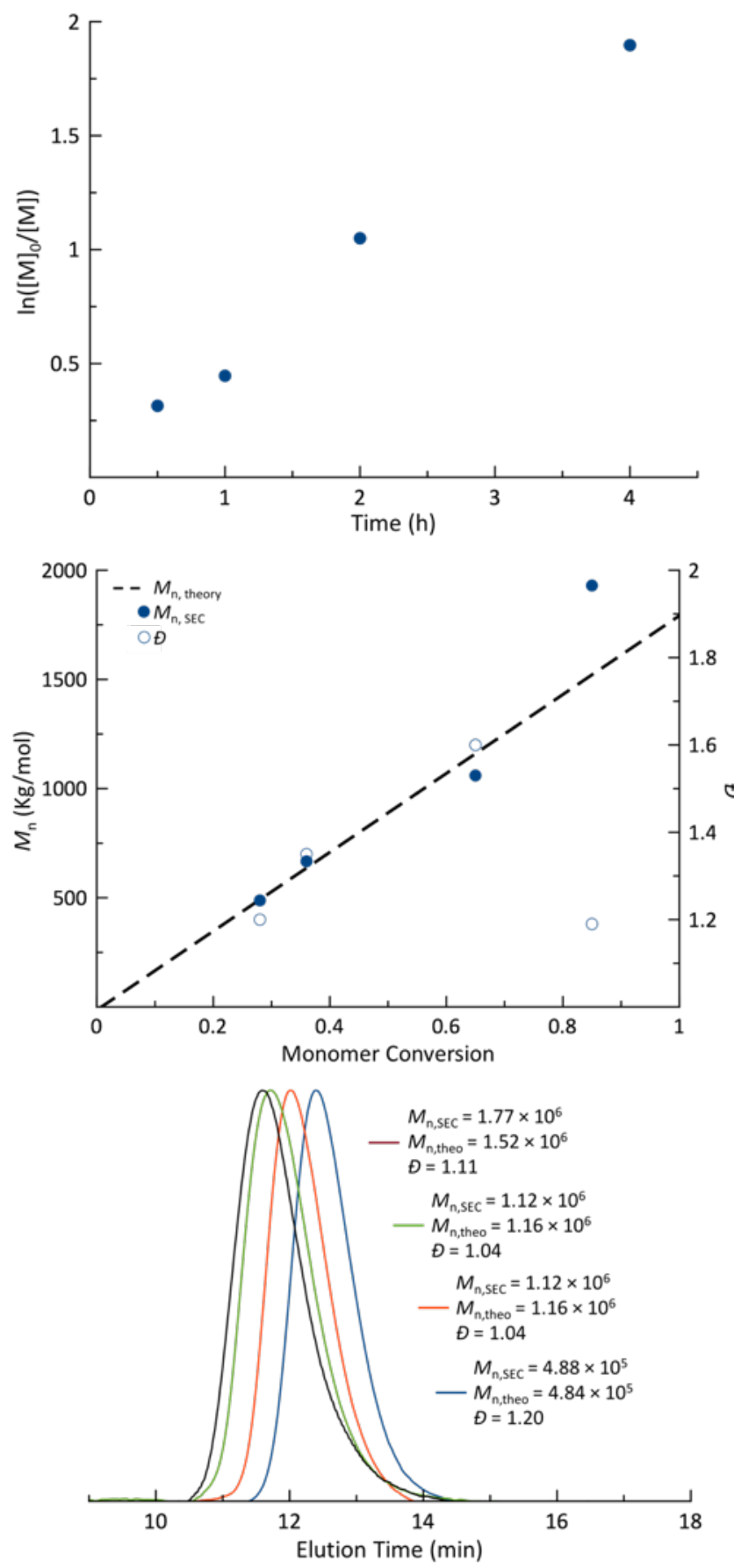

Figure S2. Ultra-high molecular weight poly(methyl acrylate) synthesis was performed in polar aprotic DMSO near room temperature $\left(35{ }^{\circ} \mathrm{C}\right)$ at $4 \mathrm{M}$ [MA]. Predetermined degrees of polymerization were targeted through the monomer to iniferter ratio. 

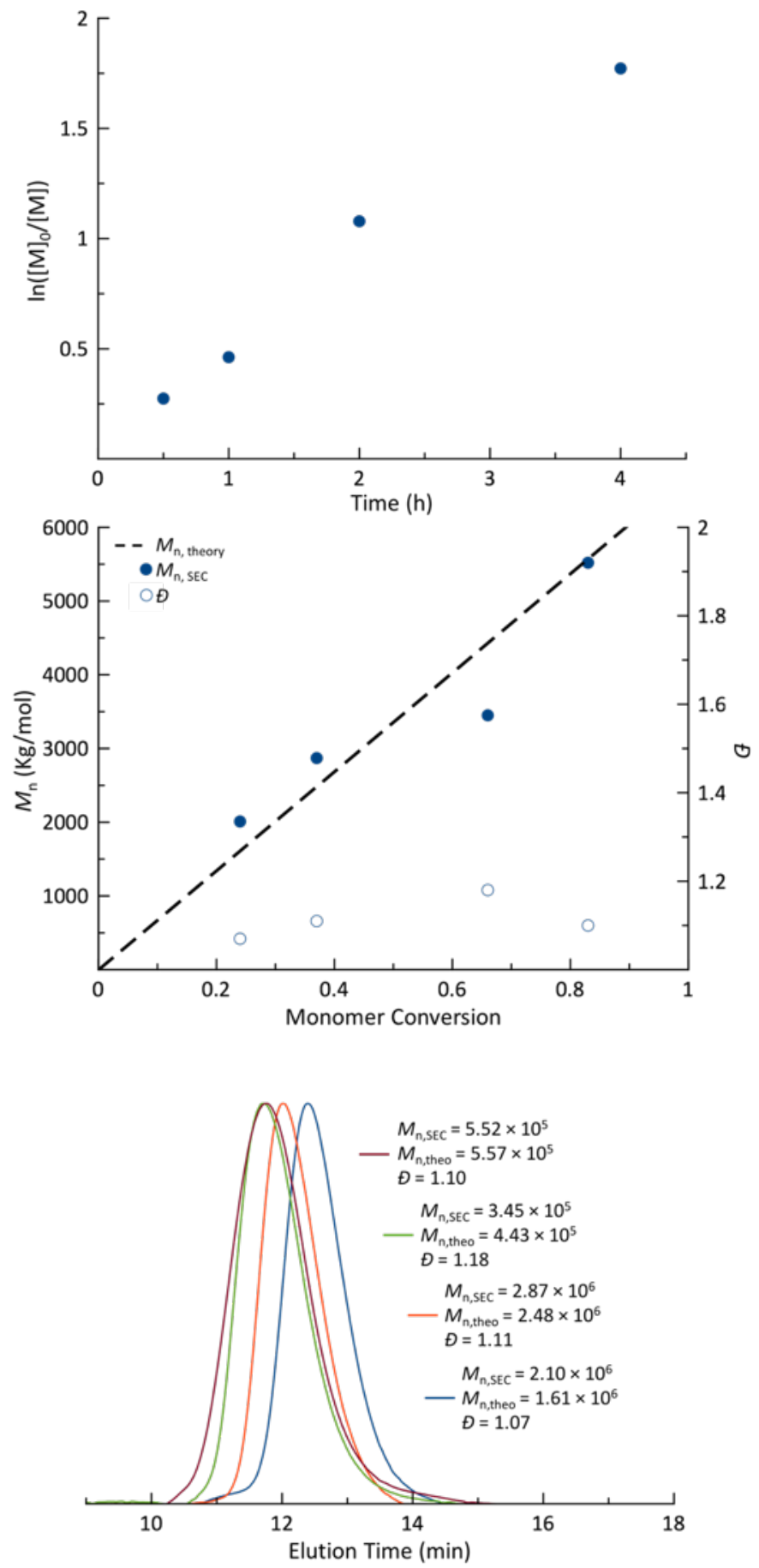

Figure S3. Ultra-high molecular weight poly(methyl acrylate) synthesis was performed in polar aprotic DMSO near room temperature $\left(35^{\circ} \mathrm{C}\right)$ at $4 \mathrm{M}$ [MA]. Predetermined degrees of polymerization were targeted through the monomer to iniferter ratio. 



Figure S4. Ultra-high molecular weight poly $(N, N$-dimethyl acrylamide) synthesis was performed in polar aprotic DMSO near room temperature $\left(35^{\circ} \mathrm{C}\right)$ at $4 \mathrm{M}$ [DMA]. Predetermined degrees of polymerization were targeted through the monomer to iniferter ratio. 

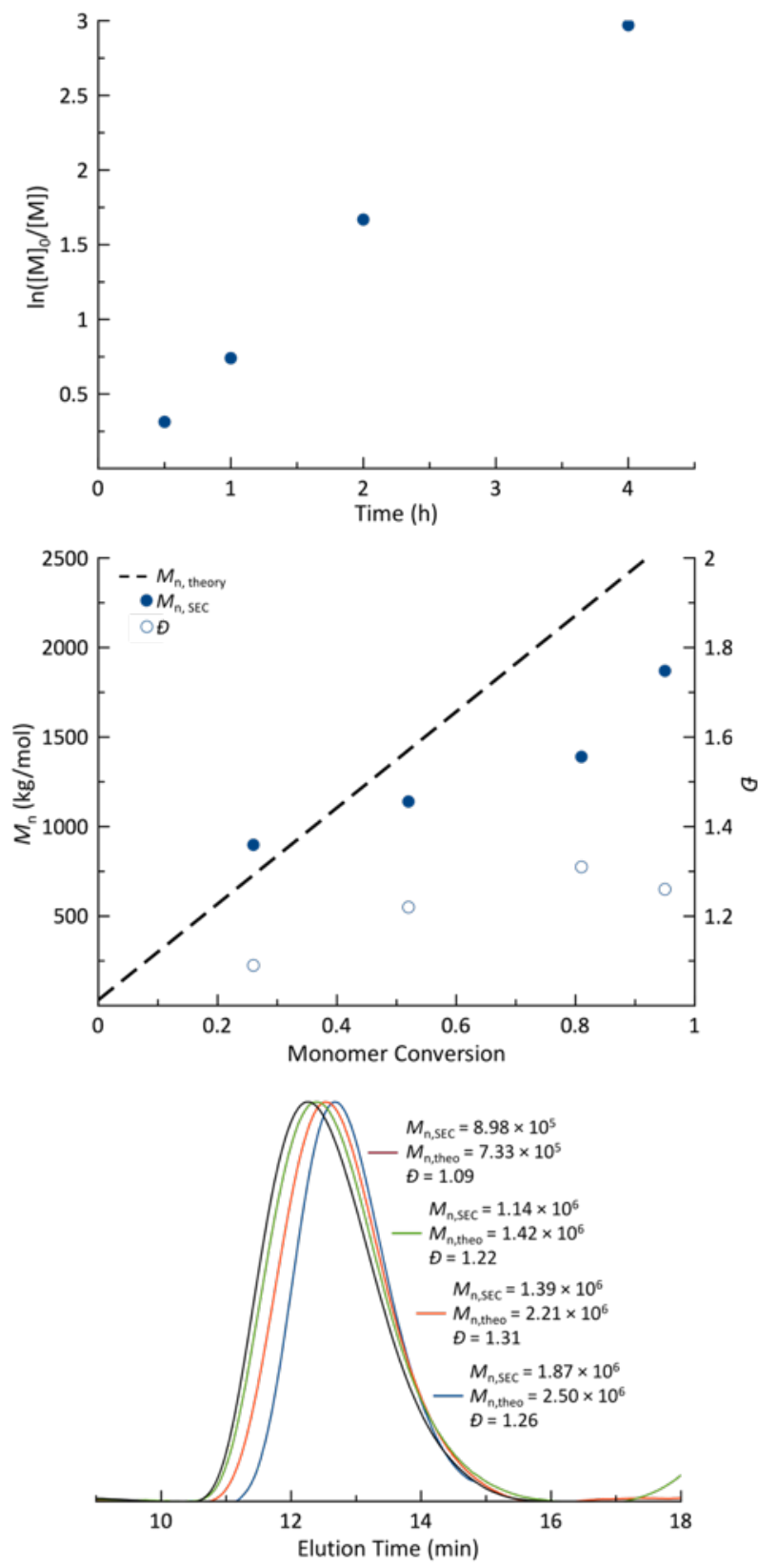

Figure S5. Ultra-high molecular weight poly $(N$-acryloyl morpholine) synthesis was performed in polar aprotic DMSO near room temperature $\left(35^{\circ} \mathrm{C}\right)$ at $4 \mathrm{M}[\mathrm{NAM}]$. Predetermined degrees of polymerization were targeted through the monomer to iniferter ratio. 

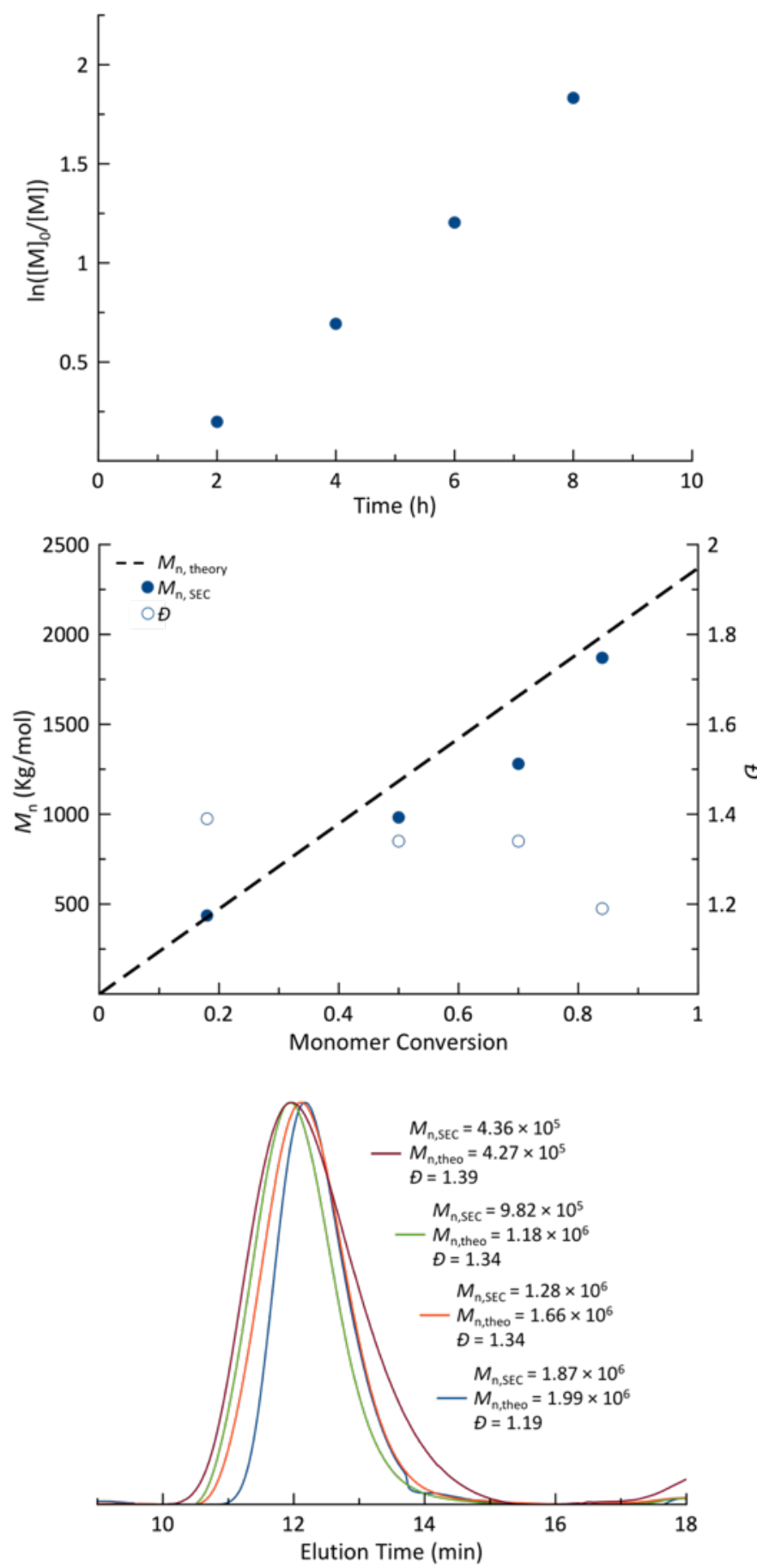

Figure S6. Ultra-high molecular weight poly ( $N$-isopropyl acrylamide) synthesis was performed in polar aprotic DMSO near room temperature $\left(35^{\circ} \mathrm{C}\right)$ at $4 \mathrm{M}$ [NIPAM]. Predetermined degrees of polymerization were targeted through the monomer to iniferter ratio. 


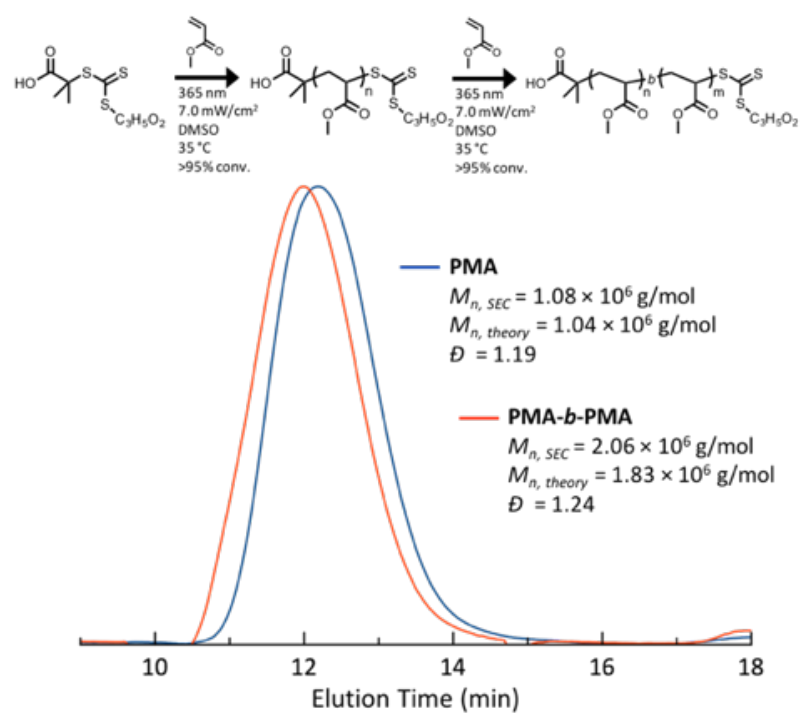

Figure S7. Ultra-high molecular weight poly(methyl acrylate)-block-poly(methyl acrylate) was prepared in a one-pot method upon near-quantitative conversion of the first PMA homopolymer.
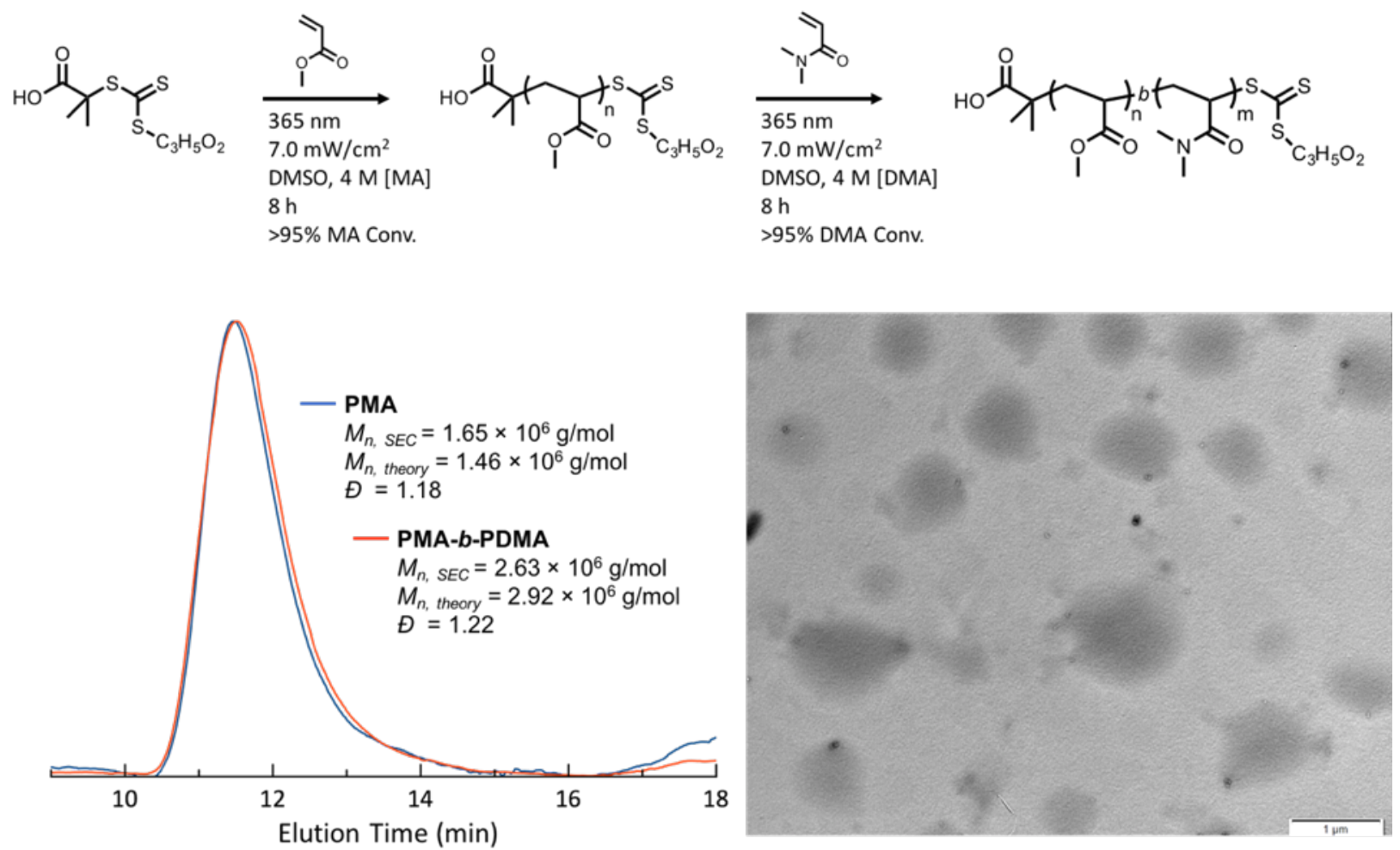

Figure S8. Ultra-high molecular weight poly(methyl acrylate)-block-poly( $N, N$ '-dimethyl acrylamide) was prepared in a one-pot method upon near-quantitative conversion of the first PMA homopolymer. A solution of PMA- $b$-PDMA $(5 \mathrm{ng} / \mathrm{mL})$ was prepared in THF and dialyzed against water to promote self-assembly. The image on the right is the dry-state TEM micrograph. 

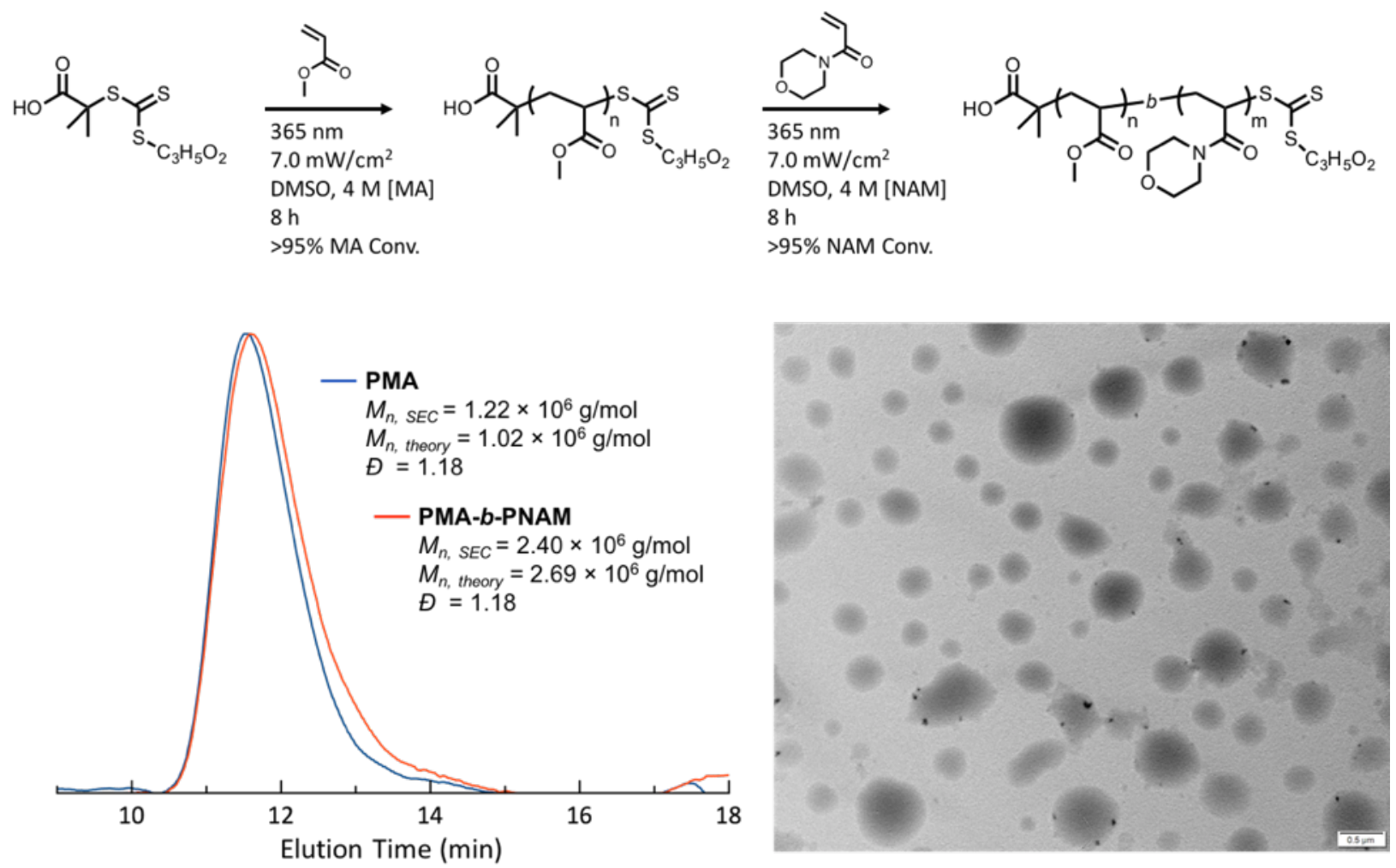

Figure S9. Ultra-high molecular weight poly(methyl acrylate)-block-poly( $N$-acryloyl morpholine) was prepared in a one-pot method upon near-quantitative conversion of the first PMA homopolymer. A solution of PMA- $b$-PNAM $(5 \mathrm{ng} / \mathrm{mL})$ was prepared in THF and dialyzed against water to promote self-assembly. The image on the right is the dry-state TEM micrograph. 

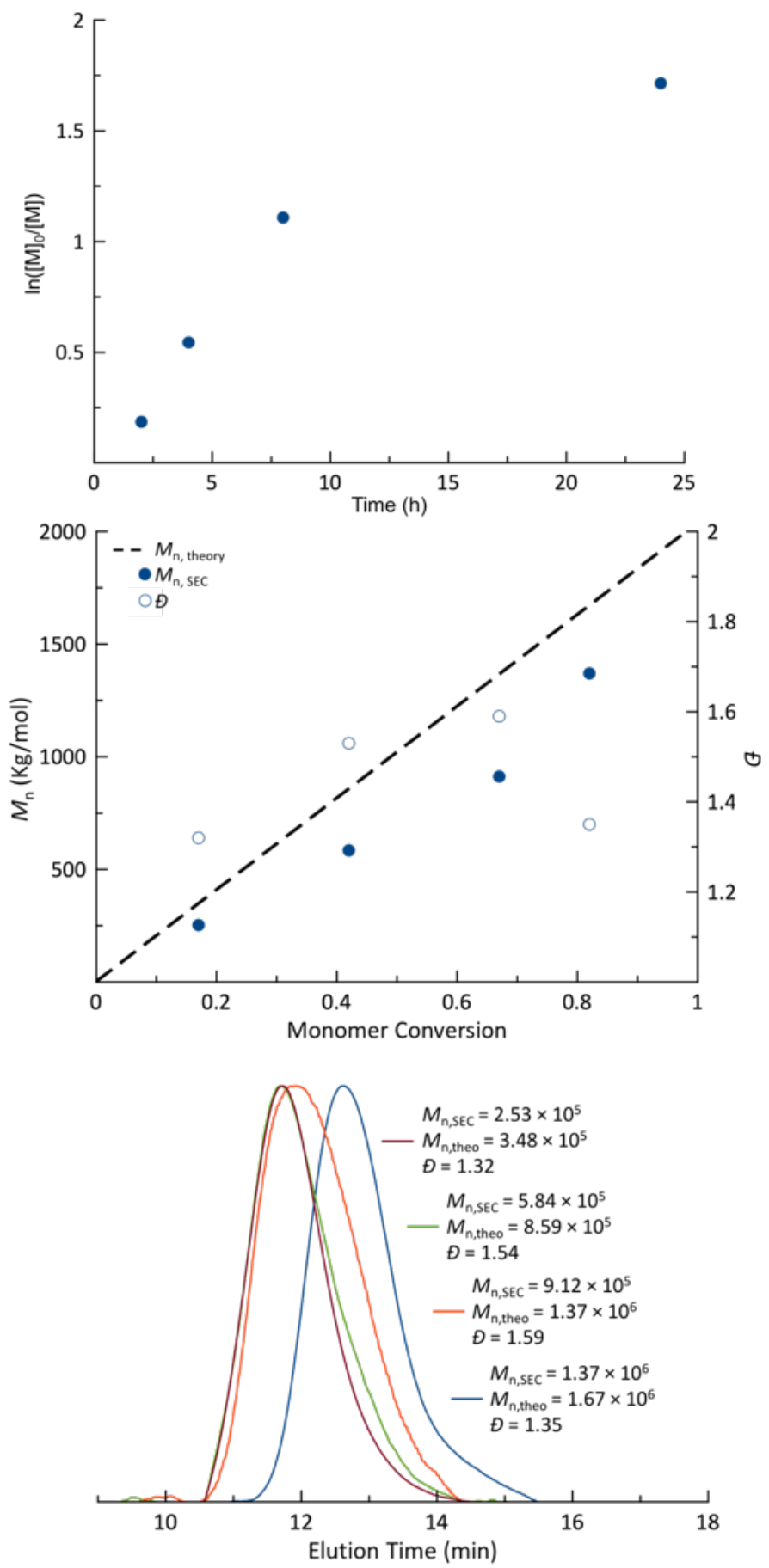

Figure S10. Ultra-high molecular weight poly(methyl methacrylate) synthesis was performed in polar aprotic DMSO near room temperature $\left(35^{\circ} \mathrm{C}\right)$ at $4 \mathrm{M}[\mathrm{MMA}]$ in the presence of a tertiary amine $N, N, N^{\prime}, N^{\prime \prime}, N^{\prime \prime}$-pentamethyldiethylenetriamine, PMDETA ([PMDETA]:[iniferter] = 1:1). Predetermined degrees of polymerization were targeted through the monomer to iniferter ratio. 

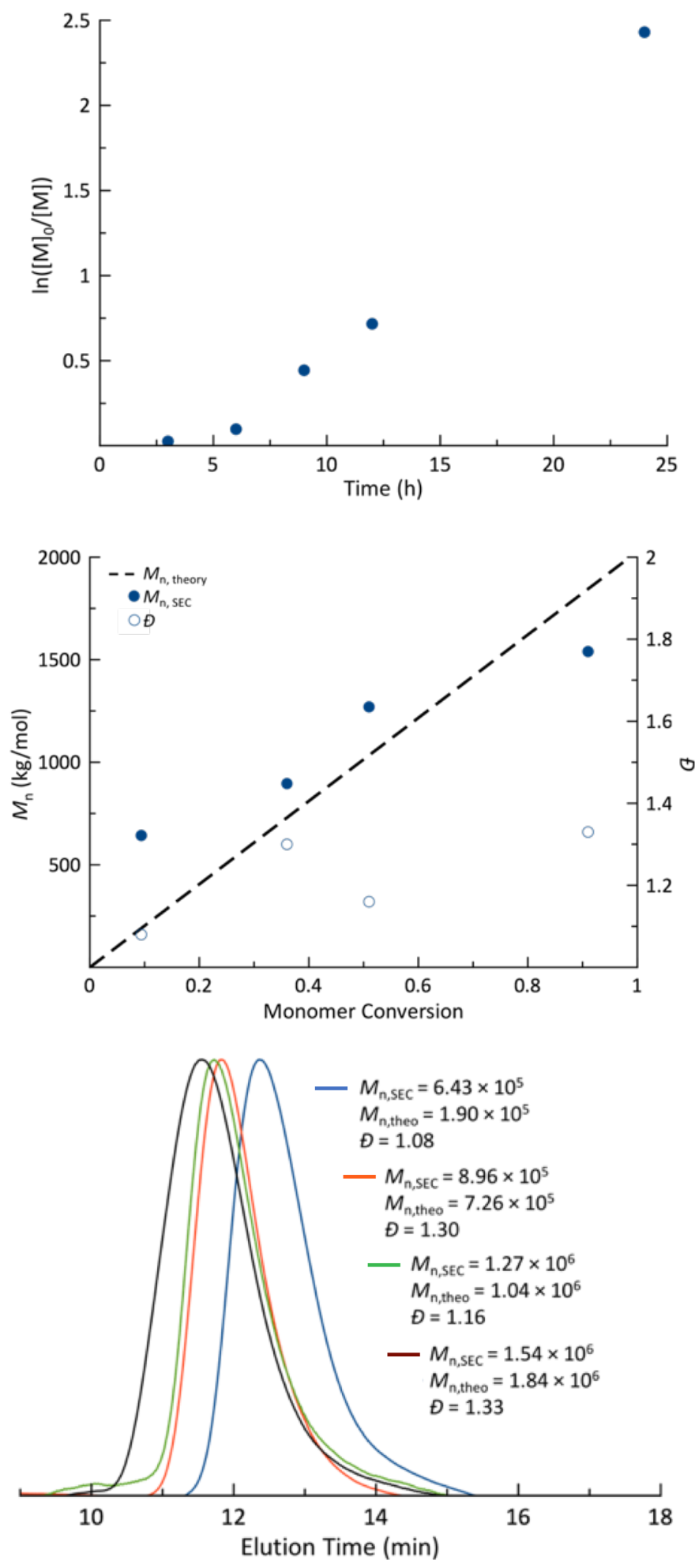

Figure S11. Ultra-high molecular weight poly(styrene-alt-maleic anhydride) synthesis was performed in polar aprotic dioxane near room temperature $\left(35^{\circ} \mathrm{C}\right)$ at $4 \mathrm{M}$ [S], [MAn]. Predetermined degrees of polymerization were targeted through the monomer to iniferter ratio. 

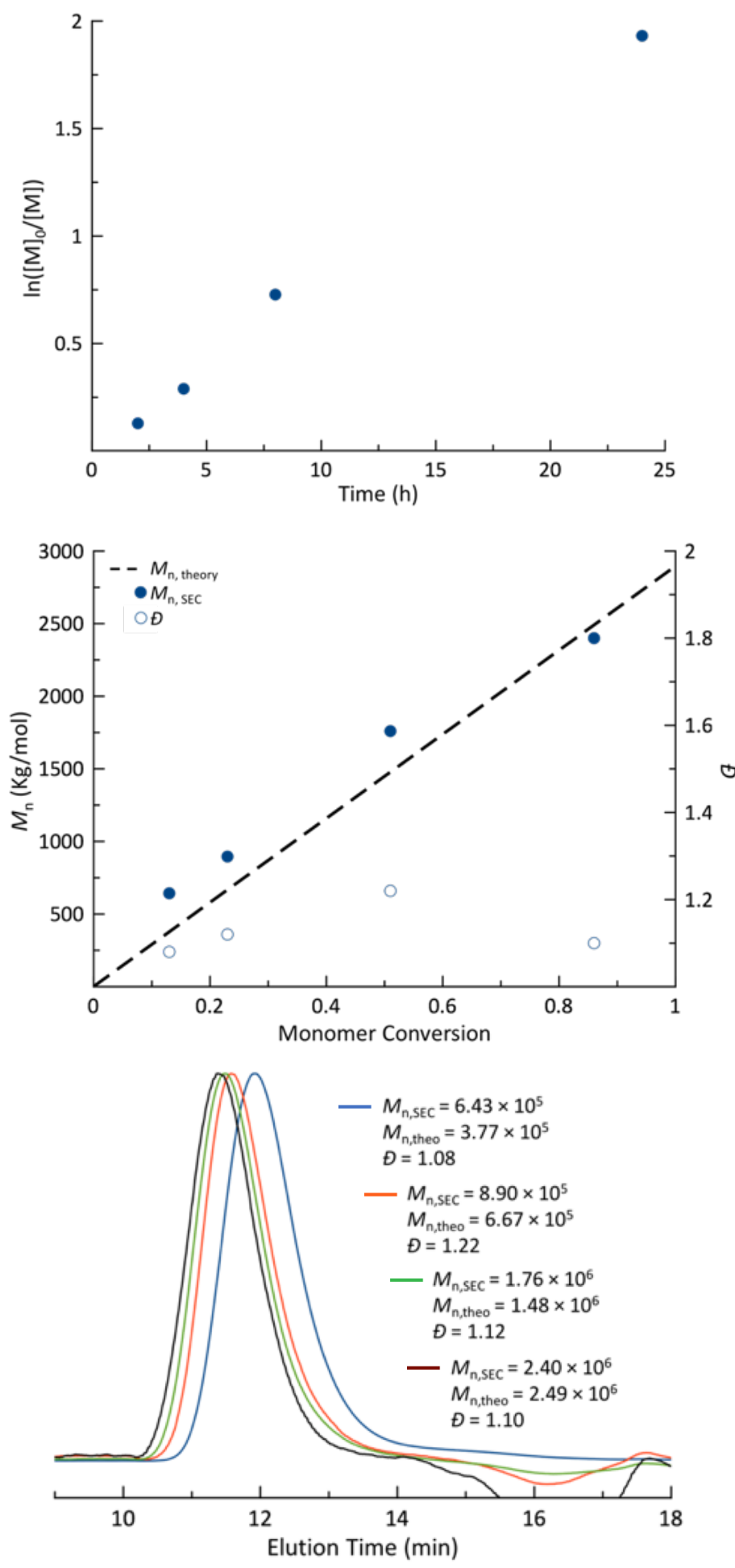

Figure S12. Ultra-high molecular weight poly(styrene-alt-benzyl-maleimide) synthesis was performed in polar aprotic dioxane near room temperature $\left(35^{\circ} \mathrm{C}\right)$ at $4 \mathrm{M}$ [S], [BzMIm]. Predetermined degrees of polymerization were targeted through the monomer to iniferter ratio. 